\title{
Os J ogos Olímpicos na Cidade do México 1968: discursos oficiais, da mídia e da literatura científica
}

CDD. 20.ed. 796.48

http://dx.doi.org/10.1590/1807-55092015000300383
Bárbara Schausteck de ALMEIDA* André Mendes CAPRARO* Wanderley MARCHI J UNIOR*
*Setor de Ciências Biológicas, Universidade Federal do Paraná

\section{Resumo}

0 presente artigo propõe uma análise histórica sobre os principais fatos relacionados à candidatura, eleição e realização dos Jogos Olímpicos de 1968 na Cidade do México, verificando a presença ou ausência desses e de outros debates no jornal Folha de S.Paulo do ano de 1968, nos relatórios oficiais emitidos pelo Comitê Organizador do evento e na literatura científica. Assim, foram identificados e descritos o processo de candidatura e eleição da Cidade do México, assim como os debates acerca da altitude e as manifestações político-sociais durante o processo de preparação e realização do evento - especificamente ao chamado Massacre de Tlatelolco e ao ato de levantar os punhos dos atletas Tommy Smith e John Carlos no pódio olímpico. Sem a pretensão de esgotar a descrição dos acontecimentos daquele evento, tais fatos apontam para relevantes indícios daquela edição dos Jogos Olímpicos. Apesar da especificidade histórica daquele contexto político e esportivo, alguns debates permanecem como desafios para as cidades sedes e para as instituições esportivas mesmo após quase meio século.

Palavras-chave: Jogos Olímpicos; Cidade do México; Mídia; Pesquisa histórica.

\section{Introdução}

A reuniáo do Comitê Olímpico Internacional no dia 2 de outubro de 2009 indicou para o Brasil, num primeiro momento, uma oportunidade sem precedentes para o esporte nacional, já que o mesmo país sediaria, no mais curto intervalo possível de tempo, talvez os dois maiores eventos esportivos do mundo: a Copa do Mundo FIFA em 2014 e os Jogos Olímpicos e Paralímpicos no Rio de Janeiro em 2016.

$\mathrm{Na}$ "tempestade" de informações decorrentes, alguns dados foram incorretamente veiculados pelo senso comum ou pela mídia, como um possível ineditismo de um mesmo país sediar tanto uma Copa do Mundo de Futebol quanto os Jogos Olímpicos em tão pequeno intervalo de tempo. Entretanto, numa revisão dos países e cidades sedes desses eventos, é possível verificar que uma situação semelhante ao caso brasileiro aconteceu em outros momentos, como no México em 1968 e 1970, na Alemanha em 1972 e 1974 e nos Estados Unidos em 1994 e $1996^{1-2}$.
Outro equívoco foi na informação de que o Rio 2016 seria a primeira edição dos Jogos Olímpicos na América Latina, já que o evento, na verdade, aconteceria pela primeira vez na América do Sul. Esse engano precisou ser corrigido na Folha de S.Paulo, importante jornal brasileiro, em sua edição de 8 de novembro de $2009^{3}$, onde se lia na errata:

Cotidiano (10 out, p.C2) Diferentemente do informado no texto "Aplicação da lei às Olimpíadas", os Jogos Olímpicos de 2016, no Rio, serão os primeiros com sede na América do Sul, e não na América Latina. Em 1968, o evento ocorreu na Cidade do México (p.3).

Esse erro cometido pela reportagem da Folha de S.Paulo reforça o que acreditamos ser um desconhecimento sobre um período histórico esportivo interessante e relativamente próximo à realidade brasileira. Sem desconsiderar os casos ímpares da Alemanha e dos Estados Unidos, propomos nesta pesquisa um olhar mais atento ao caso mexicano, pelas suas similaridades ao caso brasileiro, como potência regional 
latino-americana que se torna sede de megaeventos esportivos. Aqui, focamos no contexto de eleição e realização dos Jogos Olímpicos de 1968 como opção de recorte temporal metodológico, por entender que tal edição teve uma relevância histórica singular no que se refere ao contexto esportivo, político e social, que é pouco conhecida ou abordada na literatura científica brasileira em eventos esportivos.

\section{Método}

Como fontes, utilizamos a literatura científica internacional, o jornal Folha de S.Paulo e os relatórios oficiais do comitê organizador e das instituiçóes esportivas relacionadas (Comitê Olímpico Internacional - COI - e do Comitê Olímpico Mexicano - COM). Em situações pontuais, outras referências foram mobilizadas, com finalidade ilustrativa ou complementar aos dados apresentados nas fontes principais.

A literatura científica internacional nos serve como base e ponto de partida para posteriormente confrontar um esperado olhar local dado pela Folha de S.Paulo, assim como a postura parcial dos documentos oficiais. A busca dos artigos foi realizada na base de dados EBSCO Host a partir do termo em inglês "Mexico" com filtros a partir dos assuntos em inglês "Jogos Olímpicos" ("Olympic Games") e "esporte" ("sport"), entre outras variaçóes (plural, singular e outras nomenclaturas para dadas em inglês para os Jogos Olímpicos - Olympics e Olympiad). Como resultados iniciais, tivemos 54 artigos de revistas como o International Journal of the History of Sport (em que se destaca o volume 26, número 6 de maio de 2009 dedicado ao evento de 1968), Sport in Society, Sport in History, entre outros artigos em que novamente as palavras chave não estavam relacionadas diretamente aos Jogos Olímpicos e por isso foram excluídos da seleção. Com isso, restaram 17 artigos que foram considerados neste trabalho.

As problemáticas desenvolvidas nos artigos foram apresentadas, num primeiro momento, conforme o período histórico ao qual se referiam - se ao processo de candidatura e eleição da Cidade do México ou às questóes emergentes no processo de preparação e realização do evento. Num segundo momento, as informaçóes foram agrupadas em temas relativos a cada período histórico. Sobre o processo de candidatura e eleição, descrevemos as etapas, os personagens e seus objetivos com a candidatura, as cidades concorrentes, os principais embates
Por isso, o presente estudo propóe uma análise histórica sobre os principais fatos relacionados à candidatura, eleição e realização dos Jogos Olímpicos de 1968 na Cidade do México, verificando a presença ou ausência desses e de outros debates em um jornal brasileiro do período, nos relatórios oficiais emitidos pelas instituiçóes esportivas responsáveis por sua organização e nas publicações acadêmicas.

políticos e o processo da eleição. E sobre o processo de preparação e realização do evento, as informaçóes foram agrupadas em dois macro debates: a altitude $\mathrm{e}$ as manifestaçóes político-sociais - estas divididas no caso do Massacre de Tlatelolco e no caso da saudação de Tommy Smith e John Carlos no pódio olímpico.

A consulta à Folha de S.Paulo (sobre o jornal, consultar Capelato e Mota ${ }^{4}$ ) foi feita pelo seu acervo online, utilizando como critério as notícias veiculadas no ano de 1968 e como palavras-chave para busca a combinação de termos: olímpico México 1968. Tivemos um total de 118 páginas como resultado dessa primeira busca, que acabaram por incluir notícias em que as palavras chave estavam desvinculadas; numa nova seleção, 31 páginas traziam informaçóes diretamente relacionadas aos Jogos daquele ano. Porém, aqui foram consideradas apenas nove reportagens, pois diziam respeito à eleição e/ou à realização dos Jogos Olímpicos de 1968 para além das informaçóes puramente esportivas - atletas convocados, seletivas e resultados dos eventos - sendo por isso objeto de análise.

A utilização de material jornalístico como fonte de pesquisa possibilita o acesso a informaçóes relativamente cotidianas durante um determinado período histórico. Ao mesmo tempo, exige um conhecimento sobre as condiçôes de produção e averiguação das temáticas veiculadas, cuja subjetividade e a presença de interesses, valores e discursos ideológicos sáo reconhecidas 5 . Aqui, chamamos a atenção para o fato que, no ano analisado, o Brasil estava sob o regime ditatorial, no qual foram marcadas as açóes repressoras de censura à mídia; mas as intervençôes e as políticas também se dão no sentido de modernização do campo das comunicaçóes, o que abriu margem para favorecimento ou destruição de mídias de acordo com as inclinaçóes políticas e ideológicas $^{6}$. Em conjunto, esses dados possibilitam afirmar que as notícias que são analisadas podem ter sido filtradas conforme tais inclinaçôes. Outro dado relevante é o fato que, na década de 60 , cerca de $30 \%$ 
da população brasileira vivia em áreas urbanas e o baixo desenvolvimento tecnológico resultava em meios de comunicação, jornais inclusive, eminentemente voltados ao público local das capitais?

Como nosso objetivo não está nos meios de comunicação, mas sim em considerar as notícias como indícios de veiculaçâo de informaçôes sobre o evento no Brasil, comparamos as matérias jornalísticas com as demais fontes, com o objetivo de compreender o olhar dessa mídia brasileira para os fatos - ou como se deu a relação entre os fatos globais, percebidos e evidenciados na literatura e nos relatórios, e a importância ou ênfase que tais fatos receberam por essa mídia localmente.

Por fim, foram revisados ainda os três números que compóem o relatório oficial produzido pelo Comitê Organizador dos Jogos Olímpicos de 1968, disponível "online". As informaçóes ali presentes foram úteis no sentido de prover o ponto de vista oficial da organizaçáo sobre todo o processo, da candidatura e eleição à sua realizaçáo. Em especial, foi possível complementar os dados relativos ao processo de candidatura e eleição apontados na literatura, assim como perceber a "defesa" sobre

\section{Resultados}

\section{A candidatura da cidade do México: o processo de eleição}

Similar ao processo atual, a eleição para a cidade sede dos Jogos Olímpicos de 1968 contou com a postulação de candidatura de várias cidades, a análise de documentos e uma votaçáo secreta e individual por parte dos membros do COI conforme disposto na Carta Olímpica - documento regulador que, entre outras coisas, estabelece os critérios para eleição da cidade sede dos Jogos Olímpicos ${ }^{a}$. De acordo com o relatório produzido pelo Comitê Organizador, a candidatura foi iniciada em 7 de dezembro de 1962, com a Cidade do México enviando 180 páginas de respostas a um questionário do COI entre outras informaçōes sobre as infra-estruturas e eventos já realizados, com destaque para a realizaçáo dos Jogos Centro Americanos em 1926 (sobre este, consultar BREWSTER ${ }^{9}$ e McGeHeE ${ }^{10}$ ). Posteriormente, novas respostas foram encaminhadas, sendo que a maior preocupação foi em justificar, através das descobertas médicas de então, que a atitude e aclimatação não seriam problemas ou perigos aos atletas ${ }^{11}$.

Em 18 de outubro de 1963, na 60 Reuniâo Geral do COI em Baden-Baden, Alemanha, a Cidade a realização do evento na altitude e a ausência de qualquer referência aos movimentos político-sociais.

Assim sendo, neste trabalho temos dois objetivos específicos. O primeiro é descrever o processo de candidatura da Cidade do México, sua eleiçáo como cidade sede e a realização dos Jogos Olímpicos de 1968, apresentados na sequência. Com a apresentação dessas informaçóes, o segundo objetivo específico é discutir algumas das conjunturas sociais e políticas que compuseram o contexto deste evento esportivo. Posteriormente, os principais achados da pesquisa são retomados com a indicação de possíveis frentes de diálogo com o caso brasileiro na discussão.

Embora tenham sido as semelhanças entre os casos de México e Brasil que tenham inspirado a realização desta pesquisa, optamos por fazer o levantamento histórico para ter uma visão mais clara das semelhanças e diferenças para o caso brasileiro, sem realizar um estudo comparativo nesse momento. Mas a existência de uma análise histórica comparativa entre o caso da Cidade do México 1968 e da África do Sul $2010^{8}$ reforça a possibilidade de comparação também para o caso brasileiro.

do México foi eleita logo na primeira rodada de votação, vencendo com a maioria de 30 votos dos 58 totais as candidaturas de Detroit (EUA), Lyon (França) e Buenos Aires (Argentina) ${ }^{12}$.

Para Brewster e Brewster ${ }^{13}$, a eleição do México parece ter sido um reconhecimento ao processo de modernização pelo qual o país passava, com crescimento econômico, investimento em infraestrutura, programas de bem-estar social, expansão do ensino superior e relativa estabilidade de governos civis ${ }^{14}$. Da mesma forma, é preciso ressaltar o desafio do México naquele momento em manter o movimento olímpico "apolítico", em uma década de Guerra Fria, Guerra do Vietná, assassinato de presidentes de potências mundiais e de Che Guevara durante sua expansão revolucionária na América Latina, declínio do colonialismo europeu, formação e disputas nos territórios africanos, entre outros movimentos civis, como de negros e de estudantes ${ }^{15}$.

Para além das questóes internacionais, BREWSTER e BREWSTER ${ }^{16}$ se debruçaram sobre a compreensão das motivaçóes por trás da candidatura em suas especificidades locais. Considerando como interessados que impuseram de cima para baixo o desejo 
de sediar os jogos, os autores colocam López Mateos (presidente do México de 1958 a 1964), Clark Flores (então presidente do Comitê Olímpico Mexicano e posteriormente segundo membro mexicano no $\mathrm{COI}$ ) e Marte Gómez (ex-presidente do Comitê Olímpico Mexicano e membro do COI) como núcleo de idealizadores do projeto. Eles objetivavam o crescimento do esporte mexicano no cenário internacional e acreditavam na possibilidade de alteração nas percepçóes estrangeiras sobre o país quanto a sua reputação, cujo benefício seria "imensurável". O quadro de então era de crescimento do país, não reconhecido internacionalmente; por outro lado, as impressóes externas eram de contínua subordinação e estereótipos de sujos, desesperados inescrupulosos ou inocentes vulneráveis, criados anos antes pela indústria cinematográfica norte-americana. A esperança era hospedar o evento com sucesso, para apagar para sempre a imagem de corrupção, ineficiência e desconfiança que pairava internacionalmente sobre o México e seu povo ${ }^{16}$.

Tal desconfiança externa se acentuou com as eleiçóes presidenciais mexicanas e a saída de López Mateos em 1964, momento em que o secretário executivo do Comitê Olímpico dos EUA, Art Lentz, declarou que "frequentemente quando se confia nos países da América Latina, há uma mudança no governo", o que causaria uma modificação nas pessoas encarregadas pela organização dos Jogos e tornariam as coisas naquele momento "bagunçadas", motivo pelo qual se sugeria a intervenção externa ou até a mudança do local do evento para os $\mathrm{EUA}^{17}$ (p.766). Pelo lado mexicano, declaraçôes foram dadas sobre orgulho pela oportunidade e o entendimento da realização do evento para além do triunfo no esporte, mas também pelos triunfos na moral, na cultura e na economia mexicanas ${ }^{17}$.

Nesse quadro de questionamento e desconfiança, paira a dúvida sobre o que justificaria a escolha da cidade mexicana como sede. Entretanto, em virtude da votação acontecer de forma secreta e individual por parte dos membros do COI desde aquele período até hoje, a explicação do porquê determinada cidade-sedeé eleita náo se evidencia em documentos oficiais. Diversas razōes ou motivaçóes para votar em uma cidade em detrimento de outra podem ser consideradas - como as aproximaçōes pessoais, regionais, as açóes políticas, as trocas de favores e o "lobby" ou mesmo a compra financeira de votos vêm sendo denunciadas há décadas pelo jornalista britânico Andrew JenNINGs ${ }^{18-19} \mathrm{e}$ ainda constam nas análises mais recentes ${ }^{20-22}$ - mas são difíceis de serem comprovadas. Assim, parece improvável que somente critérios técnicos ou econômicos sejam avaliados pelos membros do COI no momento da votação, levando em consideração, por exemplo, as candidaturas más sucedidas da Cidade do México para os jogos de 1956 e 1960, apesar do reconhecimento, por parte de antigos presidentes do COI, sobre o crescimento econômico, social e esportivo do país na década de $50^{16}$.

Apesar dessas variantes, três pontos são apontados pela literatura como relevantes para que a candidatura da Cidade do México para 1968 se mostrasse bem sucedida: 1) a boa relação e apoio, ainda que não explícito, com Avery Brundage, antigo presidente do Comitê Olímpico dos Estados Unidos (USOC) e presidente naquele momento do $\mathrm{COI} ; 2$ ) as tensóes ideológicas provocadas pela Guerra Fria, com o perigo de atletas não conseguirem visto para competiçôes, devido suas nacionalidades; e 3) a possibilidade de surgir uma força paralela de eventos entre países de terceiro mundo, dado o entendimento de certos privilégios às nações imperialistas quando se tratava da relação esporte e política. Sobre este último, os boicotes de cunho político que vinham ocorrendo em eventos esportivos anteriores, com suspensóes de naçóes em desenvolvimento, como China e Indonésia, mas não de naçóes como EUA e França, provocaram a criação dos "Jogos de Forças Emergentes", que em 1963 contou com 48 países de 68 convidados, tendo como principais promotores justamente China e Indonésia ${ }^{16}$.

Por essas razóes, as candidaturas de México e Argentina estavam fortificadas. Entretanto, a Argentina passava por um momento instável, tanto sob o ponto de vista político, devido à ditadura militar, como pelo econômico, devido às altas taxas de inflação, principalmente no ano da eleição para os Jogos Olímpicos ${ }^{16}$.

Independente dos reais motivos que fizeram com que a maioria dos membros votantes do COI escolhesse a Cidade do México como a sede dos Jogos Olímpicos de 1968, a opção inédita de uma cidade considerada de "terceiro mundo" não seria isenta de questionamentos e dúvidas. Mais do que isso, o evento acabou tomando contornos ainda mais conflituosos nos processos seguintes à eleição, como descrevemos a seguir.

\section{A realização dos J ogos Olímpicos de 1968: embates pré, durante e pós-evento}

As incertezas em relação à capacidade de realização do evento na Cidade do México mostradas durante o período de candidatura e eleição se estenderam em diversas direçóes nos períodos seguintes de preparação e organização do evento. Não somente às dúvidas internacionais sobre a estabilidade política e poderio 
organizacional, outro aspecto problemático era essencialmente geográfico: a questão da altitude ${ }^{16}$. Após a eleição, o próprio Comitê Organizador acentuou que a imprensa internacional duvidava do desempenho dos atletas devido às características naturais locais ${ }^{12}$.

KASPEROWSKI $^{23}$ argumenta que a discussão sobre essa questão durou por anos, entre depoimentos de atletas, técnicos, fisiologistas, médicos entre outros, que debatiam desde os riscos de mortes para atletas de longas distâncias (atividades aeróbicas) à possível melhoria nos recordes mundiais nas provas de curta distância (atividades anaeróbicas). WRYNN ${ }^{24}$ e HEGGIE $^{25}$ concordam sobre a importância dessa edição dos Jogos Olímpicos à história científica do esporte, já que a pesquisa fisiológica passa a ter uma posição extremamente relevante no atletismo, e mais especificamente no movimento olímpico, quando há uma forte influência no debate sobre os efeitos/benefícios no máximo desempenho fisiológico pelos treinos em média altitude, quando as altas altitudes já vinham sendo objeto de interesse de estudiosos do alpinismo. $\mathrm{O}$ que, naquele momento, tornava-se uma forma de aclimatização, sobre o qual o conhecimento era primitivo, hoje se tornou uma etapa na metodologia de treinamento para competiçóes em baixas altitudes $^{23-24}$. Entretanto, HegGIE ${ }^{25}$ discute que, para além do desenvolvimento da medicina esportiva como uma "nova" área de conhecimento especializado, os Jogos Olímpicos do México foram simbólicos ao questionar a retórica do amadorismo e as tensóes políticas típicas daquele momento. A autora faz essas análises a partir de uma pesquisa que toma como base a mídia, atletas e a organização esportiva olímpica da Grã-Bretanha, cuja cultura esportiva representava a ideologia amadora do esporte e passou a conviver num terreno mais racionalizado e científico.

$\mathrm{Na}$ Folha de S.Paulo, os debates médicos foram levantados às vésperas dos Jogos ${ }^{26}$, incluindo argumentos sobre as preocupações inéditas até então sobre determinação do sexo e o "doping" 27 . Ainda no quesito médico/fisiológico, foi anunciado com destaque, embora sem maiores detalhes, a notícia de que um esportista teria sido vítima da altitude no México. A notícia mostra que um treinador de luta livre teria falecido em razão de um ataque cardíaco e tal informação foi veiculada pelo Comitê Organizador dos $\operatorname{Jogos}^{28}$. Nenhuma outra fonte menciona esse caso.

Além da polêmica com relação à altitude, outros pontos são destacados sobre os Jogos Olímpicos do México em 1968. BREWSTER ${ }^{9}$, a partir de uma recuperação de informaçóes sobre os usos e incorporação do esporte no México a partir da década de 20, argumenta que:
Em grande parte da história pós-revolucionária, o Estado viu o esporte como um meio de contenção e canalização das energias da juventude mexicana para fins louváveis, é irônico que o maior evento esportivo sediado no México, os Jogos Olímpicos de 1968, aconteceu precisamente no momento que os estudantes especificamente rejeitavam as mensagens governamentais de lealdade incondicional (p.153).

A levante estudantil mencionado, que não era exclusiva no caso mexicano e teve semelhantes em todo o mundo, inclusive no Brasil ${ }^{29}$, sendo o caso francês conhecido como Maio de 1968 como o mais notório, era resultado da rejeição às autoridades paternalistas e tinha contornos políticos de diferentes frentes, como a luta por mais democracia, liberdade e emprego, e contra as guerras (naquele momento aconteciam a Guerra do Vietnã, lutas armadas na América Latina e África e a Revolução Cultural na China) ${ }^{30}$. A demonstraçáo dessa insatisfação no México acontecia em locais públicos considerados sacros pelo governo através de marchas, discursos e confronto físico. Uma dessas manifestaçóes, poucos dias antes do início dos Jogos Olímpicos, que teve grande concentração na Plaza de las Tres Culturas ficaria conhecida no futuro como o Massacre de Tlatelolco, na noite de 2 de outubro de 1968․ Um livro sobre esse episódio, escrito a partir de testemunhos de história oral, argumenta que enquanto os jornais do dia 3 de outubro de 1968 falam de 20 a 28 mortos, no decorrer dos dias esses números foram crescendo, sendo que o jornal britânico The Guardian, em uma "investigação cuidadosa", considera uma quantidade de mortos comumente mais aceita como sendo 325, com muitos outros feridos e cerca de dois mil presos. Tão incerto quanto os números finais dos mortos é a real razão para tal fato ${ }^{31}$.

$\mathrm{Na}$ edição do dia 2 de outubro, em referência à informação do dia 1, a Folha de S.Paulo noticiava que estudantes mexicanos ocupavam a Cidade Universitária, local onde se encontrava o estádio olímpico, "sem choques", anunciando que manifestaçôes durante os Jogos poderiam acontecer caso suas reivindicaçóes não fossem atendidas. Entre elas, destacavam-se: "libertação de presos políticos, destituição dos chefes de polícia responsáveis pela repressão, castigo dos culpados, dissolução do corpo de granadeiros, indenização às famílias das vítimas, e abertura de um verdadeiro diálogo entre os estudantes e as autoridades" 32 (p.5). $\mathrm{Na}$ mesma notícia se comunicava a previsão de novos comícios. No dia seguinte, em meio a uma nota sobre o retorno de uma atleta brasileira do atletismo por mau comportamento, noticia-se a entrega de 
panfletos pelos estudantes aos atletas, justificando as açóes e os objetivos dos seus movimentos, principalmente "a atletas latino americanos, mas também aos procedentes dos países do Leste da Europa, inclusive os soviéticos", que, "absolutamente, não [era] dirigido contra os Jogos"33 (p.19).

No dia 3 de outubro de 1968, quando o Massacre de Tlatelolco foi noticiado pela Folha de S.Paulo, a matéria de capa da edição da tarde anunciava: "Olimpiada [sic] ameaçada: BANHO DE SANGUE NO MEXICO [sic]: 26 MORTOS”. A reportagem brasileira contabilizava 26 mortos, sendo 25 estudantes e um militar. Conforme a notícia, a tragédia "[agravava] a tensão no país e [ameaçava], mais do que nunca, a realização dos Jogos Olímpicos" ${ }^{34}$ (p.1).

Telegramas entre a embaixada norte-americana no México e seu governo, antes confidenciais que foram tornados públicos em 2003, mostram a preocupação dos EUA com as revoltas estudantis, justificada pela segurança para os Jogos Olímpicos. Essa troca de correspondências tornou-se mais frequente a partir do final do mês de julho. Um telegrama enviado 30 de setembro e que chegou aos EUA dia 1 de outubro indica que havia o conhecimento da marcha programada para o dia 2 de outubro, mas que nenhuma permissão de intervenção tinha sido dada. Em seguida, afirmava-se que os comandantes militares teriam autorização para agir contra manifestaçóes de estudantes sem o aval do comando central ${ }^{35}$. O contato seguinte, posterior ao massacre, notificava a morte de 24 civis e oito militares com os dados ainda incompletos, na possibilidade de se chegar a 100 mortos. Nele, demonstra-se a preocupaçáo com os revoltosos após os disparos, seguida da garantia que os Jogos Olímpicos aconteceriam sem perturbações significativas aos visitantes, exceto casos isolados de violência que não poderiam ser previstos ${ }^{36}$.

A preocupação com a segurança foi evidenciada nas notícias dos dias 4, 6 e 9 de outubro na Folha de S.Paulo. Nessas datas, as notícias colocavam em xeque desde a realização do evento ("Olimpíada: adiamento em discussão"), o pedido de proteçấo por parte de comitês olímpicos ("Pedida proteção às olimpíadas"), à presença do exército na vila olímpica ("Exército guarda Vila Olimpica") 37-39.

Talvez como resposta ao Massacre de Tlatelolco e às críticas da imprensa sobre a altitude, o Comitê Organizador de 1968 criou, entre os relatórios oficiais sobre o evento, um volume exclusivo precedente aos demais dados sobre o evento para uma "compreensáo geral sobre o espírito e a natureza dos mexicanos que poderá resultar em uma melhor apreciação da recepção de coração aberto que eles ofereceram a juventude do mundo"12 (p.21[?]).

Entretanto, o Massacre de Tlatelolco em nenhum momento é citado. Pelo contrário, a seção sobre "A Vida Política" exalta as transiçôes democráticas de governos que se mantiveram no poder por seis anos, conforme o esperado e em acordo com a Constituição de 1917, e de que forma as políticas e decisōes são tomadas em seu aparato burocrático ${ }^{12}$ (p.106). Mas a preocupação em justificar de forma velada a atuação do exército se dá na subseção "México e o Mundo".

Após o discurso de um país pacífico com seus vizinhos e na política de não envolvimento em guerras, o exército é descrito como náo tendo grandes investimentos financeiros e sua atuação não se restringe a manutenção da ordem pública e da soberania nacional, mas também para períodos de desastres naturais e na cooperação de outras causas como campanhas de alfabetizaçáo e reflorestamento ${ }^{12}$.

Alguns outros elementos sáo salientados, como suas posiçôes em questôes políticas internacionais e alguns exemplos de "respeito a leis internacionais e a paz"12 (p.106). Nesse cerne está o chamado Tratado de Tlatelolco, desenhado em 1967 e assinado em 1969, quanto à proibição de teste, uso, produção ou aquisição de armas nucleares pelos países da América Latina e Caribe.

Após a grande repercussão do Massacre de Tlatelolco, as informaçóes seguintes noticiadas pela Folha de S.Paulo se restringiam aos resultados de competiçóes, em que não encontramos nenhum comentário sobre, por exemplo, o protesto realizado pelos atletas Tommy Smith e John Carlos no pódio olímpico, assim como nos relatórios oficiais do evento. A imagem dos dois atletas no pódio, descalços e com um dos punhos levantados vestindo uma luva preta se tornou icônica, chamando a atenção e a curiosidade para a causa em voga. Essa iniciativa fazia parte de um protesto maior que vinha acontecendo nos Estados Unidos no período, a favor dos direitos civis dos negros, e que, no esporte, culminava numa disputa de mais longo prazo entre atletas negros estadunidenses e as instituições esportivas olímpicas. GuTtManN ${ }^{40}$ indica que, no ano de 1967, existia uma mobilização de boicote pelos atletas negros americanos aos Jogos Olímpicos de 1968, assim como uma resistência à Avery Brundage proferida pelo próprio Tommy Smith. Não por acaso, o ato foi repudiado tanto pelo Comitê Olímpico dos Estados Unidos quanto pelo COI, que entendiam (e entendem) que manifestações políticas não devem ocorrer durante os Jogos Olímpicos. Como punição, Smith e Carlos foram expulsos imediatamente após a cerimônia de premiação, pelo 
Comitê Olímpico dos Estados Unidos, e forçados a deixar a Vila Olímpica ${ }^{41}$.

A reticência desse assunto na documentação da época poderia indicar que a valorização do ato foi, em parte, uma construção "a posteriori”, já que diversas bibliografias mais contemporâneas tratam do tema, desde artigos comerciais ${ }^{42}$, livros ${ }^{43}$ e mesmo um documentário de televisão feito pela $\mathrm{HBO} \mathrm{em}$ $1999^{44}$, além de grande parte dos artigos referenciados anteriormente aqui e inúmeros outros dedicados exclusivamente a esse tema. Apesar de terem seu gesto condenado por parte das instituiçóes esportivas e de alguns membros da sociedade americana por duas décadas, eles receberam o grau de doutores honorários pela San Jose State University em $2005^{45}$, evidenciando a posterioridade nos seus reconhecimentos.

Embora o peso daquele gesto, na atualidade, pareça ser muito maior, seria inexato afirmar que a ação tenha sido simplesmente ignorada. BREWSTER e BREWSTER ${ }^{41}$ apresentam documentos em apoio e em rejeição à atitude, emitidos em contatos entre líderes políticos e cidadãos à Brundage. Os autores apontam ainda que o impacto do ato foi relevante para os Estados Unidos, mas não teve tanta importância para o México, onde a mídia apenas noticiou a atitude e suas consequências. Nesse ponto, hipoteticamente é possível considerar que a ausência de cobertura desse acontecimento pela Folha de S.Paulo pode tanto ter sido resultado da pressão da censura da ditadura, em que um ato transgressor não seria merecedor de destaque, quanto a não percepção da profundidade e importância que tal ação possuía.

Esse caso em partes resume as condiçóes e papéis das diferentes fontes que foram utilizadas nessa pesquisa. A literatura examinada, mais recente, reconhece tal relevância, mas não identificamos a abordagem da Folha de S.Paulo e dos relatórios oficiais do evento. Ainda que a Folha de S.Paulo tenha realizado a cobertura dos marcos mencionados, com exceção do protesto de Smith e Carlos, percebe-se que naquele momento, com o decorrer das competiçóes, houve uma reorientação das notícias para os resultados esportivos. Da mesma forma, os relatórios do evento se limitam a aprofundar os detalhes em relação à preparação e realização do evento em si, o que não os excluem da utilização para compreender o contexto e os posicionamentos dessas instituiçóes em relação aos aspectos sociais e políticos mais amplos que os Jogos Olímpicos acabam por mobilizar.

\section{Discussão}

Ao revisar os Jogos Olímpicos de 1968, as três fontes escolhidas nesse estudo proporcionaram um profícuo panorama compreensivo do contexto histórico no qual o evento foi sediado na Cidade do México. Como era de se esperar, cada uma das fontes teve um olhar específico aos processos e acontecimentos que compuseram o evento, da candidatura à organização, conforme suas predisposiçóes inerentes ao papel e ao campo nos quais elas se localizam.

Conforme exposto em resposta ao primeiro objetivo específico - qual seja, descrever o processo de candidatura da Cidade do México, sua eleição como cidade sede e a realização dos Jogos Olímpicos de 1968 - os contextos de candidatura e eleição, em cada caso dos Jogos Olímpicos, dependem da conjunção de diversos fatores, tanto observáveis e passíveis de análise, tais como as condiçóes econômicas e políticas, quanto outras menos nítidas, como algumas das inclinaçôes e motivaçôes que afetam o processo decisório das instituiçôes responsáveis (COI, Comitê Olímpico Nacional e Governo postulante). Nas fontes consultadas, justificativas ou razóes para a candidatura da Cidade do México foram apontadas nos relatórios oficiais e estendidas pela literatura acadêmica, levantando outras possibilidades com base no contexto histórico - político e esportivo - que poderiam ser intervenientes.

Assim, o Comitê Organizador declarou oficialmente que buscava com o evento mostrar seu relevante crescimento econômico, de estabilidade política e de direitos sociais. Embora os relatórios sejam reticentes que essa teria sido a razão da escolha, Brewster e Brewster ${ }^{16}$ foram além e apontaram para a intenção da elite do México em mudar a visão estereotipada e até preconceituosa do país no ambiente internacional, que encontrou um campo favorável na votação do COI ao ser uma cidade fora do contexto da Guerra Fria e pertencente ao grupo dos países não desenvolvidos, que começavam a mostrar certa resistência ao modelo olímpico centrado nas potências políticas e econômicas mundiais.

A desconfiança internacional, que tentava ser combatida pelo país sede, foi identificada nas declaraçôes de representantes de outros países descritas na literatura tanto no processo de eleição como no período posterior de preparação. $\mathrm{Na}$ discussão 
de algumas das conjunturas sociais e políticas que compuseram o contexto deste evento esportivo, matéria do segundo objetivo específico, dois temas controversos emergentes foram abordados: a questão da altitude e as manifestaçóes político-sociais.

A localização da Cidade do México acima dos dois mil metros foi vista, na época, como perigosa para a saúde dos competidores, a ponto do tema sofrer reverberação em duas reportagens da Folha de S.Paulo. Apesar dessa questão em voga, a iminência da realização do evento naquela altitude resultou no desenvolvimento de estudos e novas técnicas de treinamento, em especial no atletismo, que exigiam uma racionalização médica e rompiam com a lógica esportiva amadora ainda dominante em alguns países. Outras questóes apontadas pelo jornal e na literatura foram em relação aos exames "antidoping" e à determinação do sexo dos atletas durante as competiçóes.

As manifestações político-sociais foram o segundo aspecto marcante no período de realização do evento, com especial atenção para o chamado Massacre de Tlatelolco e os punhos levantados de Tommy Smith e John Carlos. Ambos são, em certo ponto, reflexo da ebulição da insatisfação de grupos em relação às condiçóes sociais e que viam nos protestos um meio de exigir seus direitos. Nesse quesito, os Jogos Olímpicos já davam visibilidade aos protestos - ainda que numa proporção consideravelmente menor em relação aos dias atuais - pela importância que tinham para o país sede e pela cobertura da mídia internacional, na época principalmente dos jornais. Em maior ou menor grau, os dois acontecimentos tiveram repercussão e servem como referências político-sociais daquela edição dos Jogos.
Sem a pretensão de esgotar a descrição dos acontecimentos daquele evento, acreditamos que os elementos aqui expostos apontam para a relevância histórica dos Jogos Olímpicos de 1968, tanto na perspectiva política quanto médica-esportiva. Se a cientificidade aplicada ao esporte olímpico não é uma ruptura total à estrutura amadora de eventos anteriores e as manifestaçóes político-sociais não foram exclusivas naquele ano, os Jogos na Cidade do México em 1968 devem ser reconhecidos como um importante capítulo nesse processo.

Mais do que isso, para a literatura brasileira entendemos que algumas especificidades descritas para o caso mexicano se aproximam a alguns dos discursos veiculados sobre os Jogos Olímpicos e Paralímpicos no Rio de Janeiro 2016, que já vêm sendo apontados pelos pesquisadores nacionais, num exercício ainda inicial de análise. Identificamos: as suspeitas levantadas sobre a capacidade de realização do evento, a tentativa de mudança dos "estereótipos" de uma nação em relevante desenvolvimento econômico ${ }^{46}$ - e nessa linha, a sustentação governamental para realização dos projetos estruturais ${ }^{47}$-, assim como a tentativa de instaurar uma atmosfera de orgulho pela "oportunidade", apesar da decisão da candidatura partir do "bloco olímpico"48 (p.15), ou seja, da elite dirigente, esportiva, política e econômica, para a população, como visto em diversas outras ocasióes ${ }^{49}$.

Ao delinear tais possibilidades de aproximação, esperamos ter aberto a possibilidade de futuras análises comparativas, com os devidos cuidados quanto a anacronismos históricos, entre sedes de megaeventos esportivos em diferentes períodos temporais, mas com realidades geopolíticas semelhantes.

\section{Nota}

a. Os documentos analisados não possuem maiores detalhes do processo de eleição ou quem eram os membros com direito a voto no período. Se os critérios sáo semelhantes aos atuais, puderam votar os membros do COI que tiveram suas nominaçóes aceitas pelo comitê executivo e que não representavam os países com cidades candidatas ${ }^{50}$.

\section{Abstract}

The Olympic Games in Mexico City 1968: official discourses, the media and the scientific literature

This article proposes an historical analysis of the main facts regarding the bid, selection and host of the 1968 Olympic Games in Mexico City. In this process, the presence or absence of these and other facts were verified on the newspaper Folha de S.Paulo of the year of 1968, on the official documents of the 1968 Organizing Committee and at the scientific literature. Then, we have identified and described the bid and 
selection process of Mexico City, as well as the debates on altitude and the social and political manifestations - specifically, the Tlatelolco Massacre and the raised fists of Tommy Smith and John Carlos at the Olympic podium. The facts were not depleted, but we understand that the description points to relevant evidence on those Games. Even considering the historical specificity of that political and sportive context, some of the debates remain as challenges for host cities and sport organizing bodies after almost fifty years.

Key Words: Olympic Games; Mexico City; Media; Historical research.

\section{Referências}

1. International Olympic Committee. Olympic Games [cited 2013 Set 25]. Available from: http://www.olympic.org/ olympic-games.

2. Fédération Internationale de Football Association. Copas do Mundo da FIFA anteriores [citado 25 set. 2013]. Disponível em: http://pt.fifa.com/worldcup/archive/index.html.

3. Erramos. Folha de S.Paulo. 8 nov. 2009; Primeiro Caderno: A3 [citado 25 set. 2013]. Disponível em: http://acervo. folha.com.br/resultados? $\mathrm{q}=$ cotidiano $+10 \% 2$ Cout $\&$ site $=\&$ periodo=acervo.

4. Capelato MH, Mota CG. História da Folha de S.Paulo (1921-1981). São Paulo: Impress; 1981.

5. Luca TR. História dos, nos e por meio dos periódicos. In: Pinsky CB, organizadora. Fontes históricas. 2a ed. São Paulo: Contexto; 2010.

6. Rubim AAC. Democracia, cultura e comunicação no Brasil. Intercom. 1985;53:51-8.

7. Rubim AAC, Colling L. Mídia e eleiçóes presidenciais no Brasil pós-ditadura. Comun Polít. 2004;22:169-89.

8. Bolsmann C, Brewster K. Mexico 1968 and South Africa 2010: development, leadership and legacies. Sport Soc. 2009;12:1284-98.

9. Brewster K. Patriotic pastimes: the role of sport in post-revolutionary Mexico. Int J Hist Sport. 2005;22:139-57.

10. McGehee R. The origins of Olympism in Mexico: the Central American Games of 1926. Int J Hist Sport. 1993;10: 313-32.

11. Organizing Committee. Official Report of the Organizing Committee of the Games of the XIX Olympiad Mexico 1968. México, 1969. vol.2. [cited 2013 Set 25]. Available from: http://library.la84.org/6oic/OfficialReports/1968/1968v2pt1. pdf.

12. Organizing Committee. Official Report of the Organizing Committee of the Games of the XIX Olympiad Mexico 1968. México, 1969. vol.1. [cited 2013 Set 25]. Available from: http://library.la84.org/6oic/OfficialReports/1968/1968v1pt1. pdf.

13. Brewster K, Brewster C. Prologue: the genre of sport as a means to an end. Int J Hist Sport. 2009;26:711-22.

14. Brewster C, Brewster K. Mexico City 1968: sombreros and skyscrapers. In: Tomlinson A, Young C, organizers. National identity and global sports events: culture, politics, and spectacle in the Olympics and Football World Cup. New York: State University of New York Press; 2006. p.99-116.

15. Hobsbawm E. A era dos extremos. 2a ed. São Paulo: Companhia das Letras; 2003.

16. Brewster K, Brewster C. The rank outsider: Mexico City's bid for the 1968 Olympic Games. Int J Hist Sport. 2009;26:748-63.

17. Brewster K, Brewster C. Pride and prejudice: foreign perceptions of Mexico as an Olympic Host. Int J Hist Sport. 2009;26:764-89.

18. Simson V, Jennings A. Os senhores dos anéis: poder, dinheiro e drogas nas Olimpíadas modernas. São Paulo: Nova Cultural; 1992.

19. Jennings A. The new lord of the rings. London: Pocket Books; 1996.

20. Booth D. Olympic city bidding: an exegesis of power. Int Rev Sociol Sport. 2011;46:367-86.

21. Jennings A. Investigating corruption in corporate sport: the IOC and FIFA. Int Rev Sociol Sport. 2011;46:387-98.

22. Rowe D. The bid, the lead-up, the event and the legacy: global cultural politics and hosting the Olympics. Brit J Sociol. 2012;63:285-305.

23. Kasperowski D. Constructing altitude training standards for the 1968 Mexico Olympics: the impact of ideals of equality and uncertainty. Int J Hist Sport. 2009;26:1263-91. 
24. Wrynn AM. 'A debt was paid off in tears': science, IOC politics and the debate about high altitude in the 1968 Mexico City Olympics. Int J Hist Sport. 2006;23:1152-72.

25. Heggie V. 'Only the British appear to be making a fuss': the science of success and the myth of amateurism at the Mexico Olympiad, 1968. Sport Soc. 2008;28:213-35.

26. O problema da altitude. Folha de S.Paulo. 2 out. 1968; Segundo Caderno: 5 [citado 25 set. 2013]. Disponível em: http://acervo.folha.com.br/resultados?q=ol\%C3\%ADmpico+m\%C3\%A9xico+1968\&site=\&periodo=acervo.

27. Dreyfus G. Determinação do sexo: estados de ambiguidade sexual. Folha de S.Paulo, 2 out. 1968; Segundo Caderno: 5 [citado 25 set. 2013] Disponível em: http://acervo.folha.com.br/resultados?q=ol\%C3\%ADmpico+m\%C3\%A9xic o+1968\&site $=\&$ periodo=acervo.

28. Esportista é vítima da altitude. Folha de S.Paulo. 9 out. 1968; Primeiro Caderno: 13 [citado 25 set. 2013]. Disponível em: http://acervo.folha.com.br/resultados?q=ol\%C3\%ADmpico+m\%C3\%A9xico+1968\&site=\&periodo=acervo.

29. Antunes R, Ridenti M. Operários e estudantes contra a ditadura: 1968 no Brasil. Mediaçôes: Rev Ci Soc. 2007;12:78-89.

30. Thiollent M. Maio de 1968 em Paris: testemunho de um estudante. Tempo Social. 1998;10:63-100.

31. Poniatowska E. La noche de Tlatelolco. 2a ed. Cidade do México: Ediciones Era; 2007.

32. Estudantes mexicanos reocupam a Cidade Universitária sem choques. Folha de S.Paulo. 1 outubro 1968; Primeiro Caderno: 5 [citado 25 set. 2013]. Disponível em: http://acervo.folha.com.br/resultados? q=ol\%C3\%ADmpico+m\% C3\%A9xico+1968\&site $=\&$ periodo=acervo.

33. Banho de sangue no México: 26 mortos. Folha de S.Paulo. 3 out. 1968; Segundo Caderno: 1 [citado 25 set. 2013]. Disponível em: http://acervo.folha.com.br/resultados?q=ol\%C3\%ADmpico+m\%C3\%A9xico+1968\&site=\&period $\mathrm{o}=$ acervo.

34. Irenice agride e retorna. Folha de S.Paulo. 3 out. 1968; Primeiro Caderno: 17 [citado 25 set. 2013]. Disponível em: http://acervo.folha.com.br/resultados?q=ol\%C3\%ADmpico+m\%C3\%A9xico+1968\&site=\&periodo=acervo.

35. National Security Archive. Sitrep September 30, 1968. U.S. Embassy in Mexico, limited official use telegram. October 1, 1968. [cited 2013 Set 25]. Available from: http://www.gwu.edu/ nsarchiv/NSAEBB/NSAEBB99/Doc18.pdf.

36. National Security Archive. October 2 Riots. U.S. Embassy in Mexico, confidential telegram. October 3, 1968 [cited 2013 Set 25]. Available from: http://www.gwu.edu/ nsarchiv/NSAEBB/NSAEBB99/Doc19.pdf.

37. Olimpiada: adiamento em discussão. Folha de S.Paulo. 4 de outubro de 1968; Primeiro Caderno: 20 [citado 25 set. 2013]. Disponível em: http://acervo.folha.com.br/resultados?q=ol\%C3\%ADmpico+m\%C3\%A9xico+1968\&site=\& periodo=acervo.

38. Pedida proteção às olimpiadas. Folha de S.Paulo. 6 de outubro de 1968; Primeiro Caderno: 14 [citado 25 set. 2013]. Disponível em: http://acervo.folha.com.br/resultados?q=ol\%C3\%ADmpico+m\%C3\%A9xico+1968\&site=\&period $\mathrm{o}=$ acervo.

39. Exército guarda Vila Olimpica. Folha de S.Paulo. 9 de outubro de 1968; Primeiro Caderno: 13 [citado 25 set. 2013]. Disponível em: http://acervo.folha.com.br/resultados?q=ol\%C3\%ADmpico+m\%C3\%A9xico+1968\&site=\&period $\mathrm{o}=$ acervo.

40. Guttmann A. The Olympics: a history of the Modern Games. Urbana: University of Illinois; 1992.

41. Brewster K, Brewster C. Mexico City’s hosting of the 1968 Olympic Games. Int J Hist Sport. 2009;26:840-65.

42. Murphy A. Where are they now? Sport Illust. 2008;109:84-96.

43. Bass A. Not the triumph but the struggle: the 1968 Olympics and the making of the black athlete. Minneapolis: University of Minnesota; 2002.

44. John Carlos and Tommy Smith are heroes in 'Fists of freedom'. The New York Amsterdam News. 12-18 ago. 1999. [cited 2013 Set 25]. Available from: http://connection.ebscohost.com/c/articles/2174458/john-carlos-tommy-smith-are-heroes-fists-freedom.

45. Coakley J. Sport in society: issues and controversies. 9th ed. New York: McGrawHill; 2007.

46. Ouriques N. Olimpíada 2016: o desenvolvimento do subdesenvolvimento. Motrivivência. 2009;21:126-55.

47. Proni MW. Observaçóes sobre os impactos econômicos esperados dos jogos olímpicos de 2016. Motrivivência. 2009; 21:49-70.

48. Mascarenhas F, Athayde PFA, Santos MR, Miranda NN. O bloco olímpico: Estado, organizaçáo esportiva e mercado na configuração da agenda Rio 2016. J Latin Am Socio-Cult Stud Sport. 2012;2:15-32.

49. Tavares O. Quem são os vencedores e perdedores dos Jogos Olímpicos? Pensar Prát. 2005;8:69-84.

50. International Olympic Committee. Olympic Charter. In force as from 8 July 2011. [cited 2013 Set 25]. Available from: http://www.olympic.org/Documents/olympic_charter_en.pdf. 
Bárbara Shausteck de Almeid Centro de Pesquisas em Esporte, Lazer e Sociedade (CEPELS)

R. Coração de Maria, 92

Recebido para publicação: 27/ 06/2012

1a. Revisão: 23/07/ 2013

80210-132 - Curitiba - PR - BRASIL

2a. Revisão: 25/09/2013

e-mail: barbara.edf@ufpr.br

Aceito: 23/ 10/2013

Rev Bras Educ Fís Esporte, (São Paulo) 2015J ul-Set; 29(3):383-93• 393 